\title{
Procesos extractivos, territorio y autonomía indígena. El pueblo mapuche en Neuquén
}

Extractive processes, territory, and indigenous autonomy. The Mapuche people in Neuquén

Processos extrativos, território e autonomia indígena.
O povo mapuche em Neuquén

Sabrina Aguirre*

\section{RESUMEN}

Este trabajo analiza la trayectoria de la organización supraco-

Palabras clave: munitaria mapuche de la provincia de Neuquén- ubicada en la cabecera de la Patagonia argentina- desde la década de 1990 a la de 2010, con el fin de caracterizar el desarrollo de una línea de acción política basada en la relación entre territorio y autoprocesos extractivos, pueblo mapuche, territorio. nomía dentro de la misma. Uno de los objetivos centrales radica en aportar a las miradas acerca de la heterogeneidad de líneas políticas y estrategias dentro del pueblo mapuche. El principal resultado del estudio se vincula a la posibilidad de observar la progresiva apertura de esta organización hacia el trabajo articulado con diferentes sectores del pueblo argentino, así como sus intentos por impulsar esta línea política en las comunidades que la componen. De esta forma, la etapa de resistencia mapuche abierta durante el neoliberalismo de los años 90, que impactó en los territorios por medio de la aceleración de la voracidad de los procesos extractivos, significó el inicio de una línea política que -a contramano de interpretaciones que la relacionan con la violencia y el separatismo- terminó orientándose hacia la identificación de problemáticas comunes con algunos sectores de la sociedad argentina y hacia el trabajo en articulación con los mismos.

* Argentina. Licenciada en Historia. Instituto Patagónico de Estudios en Humanidades y Ciencias Sociales, CONICET-Universidad Nacional del Comahue (IPEHCS-CONICET-UNCo), Neuquén, Argentina. E-mail: aguirrecarlasabrina@gmail.com 


\begin{abstract}
This paper analyzes the Mapuche supra-community organization in the province of Neuquén - located in the headwaters of Argentine Patagonia - from the 1990s to 2010 to characterize the development of a line of political action based on the relationship between territory and autonomy within it. Main objectives are contributing to the heterogeneity of political lines and strategies within the Mapuche people. The study's main result connects the possibility of observing the progressive opening of this organization towards the work articulated with different sectors of the Argentine people and its attempts to promote this political line in the communities that compose it. The Mapuche resistance stage opened with 1990s neoliberalism, which impacted the territories by accelerating the extractive processes. The latter meant the beginning of a political line that - contrary to interpretations that relate it to violence and separatism - ended up being oriented towards identifying common problems with some Argentine society sectors and working in articulation with them.
\end{abstract}

\section{RESUMO}

Este trabalho analisa a trajetória da organização supracomunitária mapuche na província de Neuquén (localizada na cabeceira da Patagônia argentina) entre as décadas de 1990 e 2010, a fim de caracterizar o desenvolvimento de uma linha de ação política baseada na relação entre o território e a autonomia dentro dela. Um dos objetivos centrais é contribuir para a visão sobre a heterogeneidade das linhas políticas e estratégias dentro do povo mapuche. $\mathrm{O}$ principal resultado do estudo está ligado à possibilidade de observar a abertura progressiva desta organização para o trabalho articulado com diferentes setores do povo argentino, bem como suas tentativas de promover esta linha política nas comunidades que a compõem. Desta forma, a etapa de resistência mapuche aberta durante o neoliberalismo dos anos 90, que impactou os territórios através da aceleração da voracidade dos processos extrativos, significou o início de uma linha política que - ao contrário das interpretações que a relacionam com a violência e o separatismo - acabou sendo orientada para a identificação de problemas comuns com alguns setores da sociedade argentina e para o trabalho em articulação com estes.
Keywords: extractive processes, Mapuche people, territory

Palavras-chave: processos extrativos, povo mapuche, território. 


\section{Introducción}

El modelo económico argentino tiene su expresión en la provincia de Neuquén -ubicada en la cabecera de la Patagonia- por medio del avance de los procesos extractivos, parte de la estrategia de acumulación de las clases dominantes, que la han configurado prácticamente como una zona de sacrificio (Risio di, Gavaldà, Pérez Roig \& Scandizzo, 2012). La noción de extractivismo puede circunscribirse a estos procesos -siempre enmarcándola en el momento actual del capitalismo y no comprendiéndola como un hecho aislado (Galafassi \& Riffo, 2018)- de apropiación de los recursos naturales en el marco de una profunda dependencia externa, la cual ha dictado la inserción argentina en el orden mundial, como proveedora de materias primas, y determinado la escasa diversificación de su matriz productiva (Gudynas, 2009). Sugerimos que existe una serie de pautas que la extracción hidrocarburífera y minera, entre otras, comparten con una actividad no frecuentemente asociada al extractivismo: el turismo. Con la existencia de desarrollos inmobiliarios que restan tierras a la producción de alimentos y precarizan territorialmente a campesinos e indígenas, el espacio rural se vuelve pasible de ser consumido en el marco de una demanda urbana de contacto con la naturaleza, lógica exacerbada cuando se trata de turismo de lujo (Torres, Pastor, Grosso \& Scoones, 2018) como parte de una forma de reproducir el capital.

Tras la conquista militar de los territorios indígenas, a fines del siglo XIX, los mapuche emprendieron procesos de reorganización de la vida comunitaria, usualmente restringidos a espacios considerados como poco atractivos para la inversión económica. A medida que las zonas rehabitadas fueron siendo objetivo de nuevas apropiaciones, se forzó a los grupos a trasladarse a áreas de cada vez mayor marginalidad (Valverde \& Stecher, 2013). A partir de la década de 1990 -en un contexto de reestructuración estatal neoliberal-, la organización supracomunitaria del pueblo mapuche en la provincia, llamada Confederación Mapuche de Neuquén, se configuró progresivamente como un actor político a tener en cuenta en la escena provincial (Kropff, 2005; Radovich, 2003; Valverde, 2005). Este hecho puede explicarse a partir de ciertos saltos cualitativos en materia de organización y desarrollo de sus líneas políticas de acción.

En este trabajo, analizaremos la trayectoria de la Confederación Mapuche de Neuquén desde la década de 1990 a la de 2010 con el fin 
de caracterizar el desarrollo dentro de la misma de una línea de acción política basada en la relación entre territorio y autonomía. Uno de los objetivos centrales radica en hacer un aporte a las miradas acerca de la heterogeneidad de las líneas políticas y estrategias dentro del pueblo mapuche. El principal resultado del estudio radica en la posibilidad de observar la progresiva apertura de esta organización hacia el trabajo articulado con diferentes sectores del pueblo argentino, así como sus intentos por impulsar esta línea política en las comunidades que la componen. De esta forma, la etapa de resistencia mapuche abierta durante el neoliberalismo de los años 90 -identificado con las gestiones de Carlos Menem en el periodo 1989-1999- que impactó en los territorios avivando la voracidad de los procesos extractivos, significó el inicio de una línea política que, a contramano de interpretaciones que la identifican con la violencia y el separatismo, se terminó orientando hacia la identificación de problemáticas comunes con algunos sectores de la sociedad argentina y hacia el trabajo, en articulación con los mismos.

El análisis presentado surge de una investigación doctoral en historia, centrada en estudiar los procesos de organización política del pueblo mapuche en la provincia de Neuquén a través del siglo XX y las dos primeras décadas del XXI. En este marco, se ha realizado un análisis de fuentes oficiales, como documentos históricos, informes de organismos provinciales y documentos producidos por las organizaciones y comunidades indígenas, así como de aquellos que han registrado declaraciones públicas de las mismas y eventos clave, como la producción periodística. Se llevó adelante un trabajo de campo etnográfico en comunidades con procesos reivindicativos activos, así como entrevistas abiertas y semiestructuradas con una serie de referentes indígenas tanto de las comunidades como de la Confederación Mapuche de Neuquén. Finalmente, se realizaron instancias de observación participante en diferentes ceremonias y eventos dirigidos por la organización supracomunal, lo cual ha sido complementado con el análisis bibliográfico.

Este escrito inicia con una revisión de los principales aportes teóricos que se toman como base del análisis del caso. Luego, se realiza una presentación de la heterogeneidad de casos de reconstitución comunitaria en la provincia a partir del desarrollo de una clasificación del 
proceso en tres tipos. Esta caracterización es central para comprender el trasfondo y las condiciones del desarrollo de la línea política estudiada. Después, el texto analiza la década de los 90 como un momento crucial para la organización indígena para a continuación abordar algunas características centrales de la visión política de la Confederación Mapuche de Neuquén que, como sostendremos, han servido como base para el impulso de la articulación con sectores del pueblo argentino como estrategia de reivindicación. Finalmente, se reduce la escala del análisis para indagar en torno a los conflictos en dos comunidades en las cuales la organización supracomunal ha impulsado la línea de acción, que es el foco de nuestro interés.

\section{Procesos extractivos y reivindicaciones mapuche}

Los procesos extractivos signan la trama de conflictividad social a nivel latinoamericano, en un momento en el que el discurso ecologista se consolida tanto en los sectores que los critican como entre los que los auspician y tiñen a toda la región con un manto de violencia, con especiales repercusiones sobre los sujetos aquí estudiados: "el extractivismo amenaza con provocar verdaderos genocidios de pueblos indígenas" (Dávalos, 2013, p. 21). Existe en ello una aparente paradoja: tanto los gobiernos como diferentes agentes internacionales han adoptado una oratoria a favor de la conservación ecológica -un "discurso verde"- y de los derechos humanos -incluso se han ratificado convenios internacionales que reconocen derechos indígenas (Dávalos, 2013). En Argentina, y particularmente en la provincia de Neuquén, esto, en tanto entra en contradicción con la dependencia externa de nuestro modelo económico, abre paso a la disputa social. El conflicto se extiende a los diferentes ámbitos del Estado, lo que no debe comprenderse como un actor homogéneo, sino uno con tensiones internas y compuesto por diferentes organismos y agencias que suelen describir derroteros en contradicción.

Se ha señalado que los procesos extractivos se relacionan con la mercantilización de la naturaleza y con el hecho de que en su desarrollo hay cuestiones a las que se les asigna un valor pasible de ser medido -como el ambiente, la contaminación y otros- en función de definir "costos de transacción" (Dávalos, 2013). Esto se puede vincular con la valoración que otros estudios han realizado acerca de las deno- 
minadas "zonas de sacrificio" (Di Risio et al., 2012): áreas "periféricas" (Seoane, 2012) afectadas por actividades altamente contaminantes, o de enclave -en las cuales el costo ambiental es absorbido por la población (Gudynas, 2013)-, y que son el origen de los excedentes que son transferidos a otras zonas (Falero, 2015). Estos espacios, sin embargo, suelen describirse desde el discurso de los sectores dominantes como zonas "vacías" y por ende "sacrificables" (Svampa, 2008). Al mismo tiempo, se realiza un avance -en la lógica de la construcción de frontera- sobre ellas que destruye las relaciones económicas, políticas, sociales y culturales preexistentes con la finalidad de constituir un nuevo territorio, es decir, nuevas reglas de juego que rijan el espacio (Borg Rasmussen \& Lund, 2018).

La conflictividad actual se encuentra atravesada por una serie de características que, por ser diferentes de los movimientos obreros del siglo XX, han sido teorizadas desde diferentes perspectivas (Walter, 2009). Este viraje ha sido descripto como un desplazamiento del locus de la conflictividad desde "la lucha por la explotación de la fuerza de trabajo al de las resistencias contra la expropiación de los territorios" (Machado Aráoz, 2015, p. 20). Ha sido también analizado en el marco de las políticas de los gobiernos "progresistas" del siglo XXI como un "giro ecoterritorial" (Svampa, 2017). Se han ensayado definiciones de conflicto, aunque también se ha resaltado que las clasificaciones no implican una pureza de estas en la realidad concreta, puesto que contenidos, intereses y experiencias históricas de los distintos actores se amalgaman (Gudynas, 2014). En este punto, debemos señalar que los conflictos mencionados en este trabajo pueden enmarcarse dentro de los socioambientales y que esta articulación de actores heterogéneos implica la presencia de objetivos diferentes detrás de la construcción de fuerzas sociales amplias.

Una línea teórica se ha abocado a vincular las formas del conflicto social al tipo de acumulación de capital (Armida, 2017; Galafassi, 2014; Pérez Roig \& Composto, 2014; Puricelli, 2017), entendiendo los procesos extractivos como una característica del capitalismo (Galafassi \& Riffo, 2018). Asumiendo la continuidad de la acumulación originaria en la actualidad (De Angelis, 2012; Perelman, 2012) -cuestión que surge del trabajo de Marx pero que ha sido rediscutida y revalorizada en las últimas décadas en, por ejemplo, Harvey (2004)-, podemos afirmar 
que la incorporación económica de áreas, hasta determinado momento pensadas como marginales, responde a la lógica de acumulación primitiva que conforma la condición para la reproducción ampliada: "los bienes comunes deben dejar su cualidad de bienes colectivos para ser bienes privados para que las relaciones sociales capitalistas fluyan mucho más libremente" (Galafassi, 2017, p. 24). La mencionada línea de trabajo sugiere que esta forma de apropiación de la naturaleza y acumulación de capital suscita contradicciones específicas que desencadenan movimientos de defensa de los recursos naturales o culturales, dentro de los cuales podemos ubicar a las disputas protagonizadas por el pueblo mapuche.

Es necesario caracterizar al territorio en su dinamismo, es decir, atravesado por procesos objetivos de construcción, por una parte, $\mathrm{y}$, por otra, por procesos subjetivos de significación. En el primero de los casos, el territorio se construye a partir de las actividades que llevan adelante las sociedades que lo ocupan para su supervivencia y reproducción (Mançano Fernandes, 2005). Esta construcción se encuentra cabalmente atravesada por la posibilidad de conflicto, puesto que en ella se ponen en juego las diferentes intenciones de uso del suelo que las sociedades portan, volviéndolo un proceso dialéctico y dinámico (Haesbaert, 2011). En el caso argentino, las políticas estatales configuraron espacios para ser habitados por el pueblo mapuche, diferentes a los originalmente habitados, y determinaron las posibilidades de desarrollo dentro de los mismos. Las características de las actividades económicas de las comunidades se vinculan profundamente con una injerencia estatal orientada a permitir la inserción nacional en términos en la economía mundial. De este modo, para analizar las posibilidades de un desarrollo autónomo de los pueblos originarios en el territorio, es necesario tener en cuenta esta característica -la dependencia- del capitalismo argentino.

La apropiación indígena del territorio, necesaria para la proyección autónoma, tiene una dimensión material, que se manifiesta en el acceso a la tierra y los recursos para controlarlos y ejercer la soberanía, y una simbólica, vinculada con los rasgos ideológicos propios de la cosmovisión mapuche. A partir de ambas, se determina la forma específica de apropiación del territorio, de la cual surgen las lógicas comunales (Escobar, 2015). La dinámica organizativa se da en torno a 
la apropiación y el control social del territorio. El pueblo mapuche tiene una forma de ser en el territorio diferente a la del pueblo argentino, en su búsqueda por recuperar la ancestralidad en los modos de vivir y de proyectarse políticamente. Se trata de lo que se ha llamado prácticas políticas ontológicas (Escobar, 2015): proyectos y formas de hacer política que se encuentran en profunda contradicción con los modos occidentales de comprender el mundo.

Como ha señalado Astrid Ulloa (2001), "los movimientos indígenas están embebidos en identidades colectivas que se reafirman a través de prácticas y elementos simbólicos que producen efectos políticos" (p. 7). En esto, es central tener en cuenta la dimensión dinámica y relacional de la construcción identitaria (García Lineras, 2014) que se vincula con los proyectos políticos construidos desde el campo indígena. Sostenemos que este dinamismo le permite a los mapuche repensar los vínculos sociopolíticos, y evaluar los impactos favorables que la socialización de ciertos reclamos pueden implicar en el camino hacia la resolución de los conflictos territoriales. La construcción de fuerzas sociales amplias en los reclamos socioambientales es un proceso a través del cual, para el pueblo mapuche, también se juega la posibilidad de detener el avance de proyectos económicos en su territorio y de consolidar la comunidad como forma organizativa y que esta sea reconocida como un interlocutor válido frente al Estado. En el seno de las articulaciones con otros sectores, estos pueden o no compartir estos objetivos de fondo, quedándose en ocasiones en intereses ecologistas, lo cual, como veremos más delante, no necesariamente implica una limitación para los indígenas.

Ya que la construcción identitaria es una elaboración abierta y en oposición a un "otro", es posible observar cómo el pueblo mapuche ha optado, en los últimos años, por no colocar en primer plano la contradicción étnica con ciertos sectores del pueblo argentino, sino que impulsar la construcción de fuerzas sociales amplias en torno a determinados reclamos, como el socioambiental. En este sentido, lejos de pensar al mapuche como un nativo ecológico (Ulloa, 2001), es necesario comprenderlo en su dimensión de actor político en el dinamismo de su identidad, de sus formas organizativas y de sus elecciones estratégicas. Entre estas últimas, la articulación con la sociedad no mapuche se perfiló durante la última década como una táctica viable para lograr 
influencia en la arena política por parte de la organización supracomunitaria de la provincia de Neuquén. Paralelamente, esta redefinición estratégica se vincula con una forma de teorizar y leer políticamente la realidad que ha llevado progresivamente a la Confederación Mapuche de Neuquén a buscar los puntos de contacto con el pueblo argentino en las múltiples opresiones atravesadas en conjunto que, en términos concretos, se enuncian identificando blancos políticos en común.

Para analizar esta cuestión concretamente, es necesario observar los contenidos del proyecto político de la organización supracomunitaria y las formas en las que la necesidad de articulación con la sociedad no mapuche se ha expresado en las prácticas impulsadas en las comunidades. Se debe tener en cuenta que, al tratarse de una organización que actualmente nuclea a 64 comunidades, en las que se expresan corrientes políticas diversas, el mantenimiento de la hegemonía es una cuestión en constante construcción, por lo que los diferentes lof -término que aquí equipararemos al de comunidad- mantienen distintos niveles de alineación con los proyectos formulados desde la organización madre en función de la heterogeneidad de situaciones que caracteriza la realidad del pueblo mapuche en Neuquén. Los contextos de recomposición comunitaria, los bagajes específicos y las formas de abordar las relaciones con otros actores definieron procesos de reconstitución política de los diferentes lof. El resultado ha configurado un panorama desafiante para la organización supracomunal. Veremos, a continuación, algunas pautas para caracterizar esta heterogeneidad interna del pueblo mapuche en Neuquén.

\section{La heterogeneidad de los procesos de reorganización comunitaria a través del siglo XX}

La situación interna del pueblo mapuche se fue configurando como diversa tras la finalización de las campañas militares de ocupación del espacio patagónico (fines del siglo XIX) en función de algunas diferencias existentes entre los procesos de recuperación de la organización basada en la comunidad. En términos de temporalidad -etapas de la recomposición- y territorialidad -consecuencia de los procesos de desarticulación y rearticulación de los núcleos familiares-, es posible observar la existencia de tres tipos de proceso. Tras la invasión armada al territorio, la presencia indígena en la región inició el retorno a las formas comuni- 
tarias de organización con el obstáculo central de la problemática territorial que fue horadando sus posibilidades de subsistencia.

A partir del rastreo de documentos oficiales, específicamente de permisos de pastoreo, de exención de pago de derechos y de permisos de ocupación, entre otros, se ha logrado establecer que desde 1885 hasta 1910 hubo un primer momento de reconstitución de algunas comunidades (Rodríguez, 1978, p. 13). En torno a la década de 1920, y hasta la de 1940, se dio una segunda etapa ${ }^{2}$. El sudoeste del territorio nacional fue, durante la primera mitad del siglo $\mathrm{XX}$, la región con una mayor proliferación de rearmado comunitario, seguido del noroeste. De un número total de cerca de 30 comunidades se compuso lo que llamaremos un primer tipo de comunidad. Parte de ellas conservaron completamente el idioma, el mapuzungun, y algunas pautas culturales, como la celebración de la rogativa ngillatun (Rodríguez, 1978, p. 96). Estas comunidades fueron las que entre 1964 y 1993 recibieron el reconocimiento oficial del Estado provincial a partir del otorgamiento de tierras fiscales bajo la forma de reservas indígenas. La región del suroeste provincial, lindera de la cordillera de los Andes, hacia fines de siglo XX concentraba la mayor parte de las comunidades ya reconstituidas, así como las más grandes

Otro grupo de familias indígenas, que consideraremos como un segundo tipo de comunidad, vio su territorialidad precarizada frente a una legislación sobre tierras que habilitaba dinámicas de despojo en favor de los grandes propietarios vinculados con las clases dominantes porteñas o locales (Blanco, 2007; 2012). Debido a ello, se obturó su reconstitución. Las migraciones forzadas en busca de inserción laboral en los ámbitos urbanos o en las tareas estacionales de la agricultura de exportación fueron la contracara de la negación del derecho al territorio (Radovich, 2013). Como consecuencia, estos procesos de reconstrucción fueron interrumpidos en momentos tempranos de la etapa en la que Neuquén estaba bajo la jurisdicción federal por ser un territorio nacional -puesto que no fue declarada provincia sino hasta 1955. Dentro del segundo tipo de comunidad, hallamos a Paicil Antriao (Villa La Angostura, al suroeste de Neuquén) -una de las agrupaciones analiza-

2 Para observar las formas de acceso indígena al territorio durante la primera mitad del siglo XX, se puede consultar Delrio (2005). 
das en este trabajo- entre aproximadamente una treintena de casos. Estos lof retomarían la reconstrucción interna a partir de la década de 1990 , la que se vería profundamente atravesada por el conflicto social general de la provincia, expresado como conflicto territorial, a raíz de los impactos de las políticas neoliberales.

Un tercer tipo de proceso fue el seguido por comunidades que tuvieron que resolver las problemáticas relacionadas con las migraciones forzosas a nuevos espacios. En efecto, todavía dentro del territorio históricamente habitado por el indígena, pero fuera de los espacios tradicionales de origen de cada familia, segundas y terceras generaciones de migrantes iniciaron los procesos de constitución de comunidades en ámbitos urbanos. Estos sujetos se encontraron en un contacto más fluido y constante con el pueblo neuquino organizado, y las generaciones más jóvenes tuvieron mayor acceso a la educación formal. Habiendo iniciado su conformación en la década de 1980, funcionaron como núcleo fundacional de una nueva línea política con un fuerte énfasis en la relación entre territorio y autonomía; cumplieron también el rol de acompañamiento y soporte de las comunidades del segundo tipo, volviéndose desde fines de los 90 la cabeza de la organización supracomunal nacida en 1970. El número de estas comunidades es reducido en comparación con las rurales -aunque son las ciudades las que concentran la mayor cantidad de población mapuche: en el ámbito de la capital neuquina, se han reorganizado dos. Una de ellas es Nawen Mapu y la otra, Puel Pvjv -el segundo caso abordado en este escrito.

Las comunidades que arribaban reconstituidas a la década de 1960 -las del primer tipo- fueron reconocidas por la provincia y se agruparon en la Confederación Indígena Neuquina, fundada en 1970 (Falaschi, 1994) -la que en el cambio de siglo modificaría su nombre a Confederación Mapuche de Neuquén. El armado de la organización supracomunitaria respondía a una serie de encuentros pautados por figuras religiosas de peso en la región, como Jaime De Nevares, configurándose como un organismo con la tarea de relevar las necesidades indígenas y organizar su transmisión a niveles estatales encargados de resolverlas ${ }^{3}$. El estrecho margen para el desarrollo de la autonomía que

3 Tal vínculo con el Estado se expresa en el Acta Fundacional de la Confederación Indígena Neuquina reproducida en Falaschi (1994). En efecto, se enunciaba la necesidad 
el vínculo con el Estado ofrecía iba a ser duramente criticado durante la década de 1990, momento en el cual ciertos conflictos territoriales se empezaron a agudizar.

La mencionada relación enmarcaba las posibilidades de resolución de las necesidades existentes. Al mismo tiempo, limitaba el desarrollo de la territorialidad mapuche en tanto la proyección autónoma no era el eje central de las políticas estatales, sino la integración indígena a la sociedad mayor (Valverde, 2005). Así, las renovadas amenazas hacia el territorio indígena que representaban las actividades extractivas, cuyas consecuencias se agravaron bajo el contexto de la aplicación de las políticas neoliberales, se conjugaron con el crecimiento de una línea política, novedosa dentro de la organización supracomunitaria, que ofrecía posibilidades de hacer frente a dichas amenazas en el marco de una proyección como pueblo mapuche. Esto, junto a otros factores que analizaremos en la siguiente sección, permitió el surgimiento de nuevas zonas dinámicas de la reconstitución comunitaria.

El apoyo de la Confederación Mapuche de Neuquén a los procesos de rearmado comunitario fue parte de su consolidación como instancia de "gobierno mapuche" (Confederación Mapuce de Neuquén, 2010), de afirmar una línea política que vincula territorio y autonomía, y constituirse como un actor con peso propio en la arena política provincial. Entre 1983 y 2015 se terminaron de reconstruir formalmente, esto es, presentaron las solicitudes para ser reconocidas por medio de una personería jurídica frente al Estado, cerca de 30 comunidades, con lo cual el total provincial prácticamente se duplicó (ver imagen 1). Durante esta etapa, la zona más dinámica en esta materia fue la comprendida entre el espacio histórico de producción hidrocarburífera de la provincia -por métodos tradicionales, el centro-este- y el recientemente incorporado a la producción gasífera y petrolera mediante métodos no convencionales (desde el norte del Departamento Confluencia hacia el de Añelo). La zona abarcó tanto los lof ubicados en zonas rurales como periurbanas y urbanas de la capital neuquina. También, tuvo gran dinamismo el extremo sur cordillerano neuquino, el que forma parte de circuitos turísticos muy difundidos a nivel nacional. Cada

de unir a los pertenecientes a la misma "raza" y elevar de forma organizada sus necesidades al Estado. 
comunidad, de los dos casos que analizaremos, pertenecen cada una a uno de estos sectores de dinamismo más reciente.

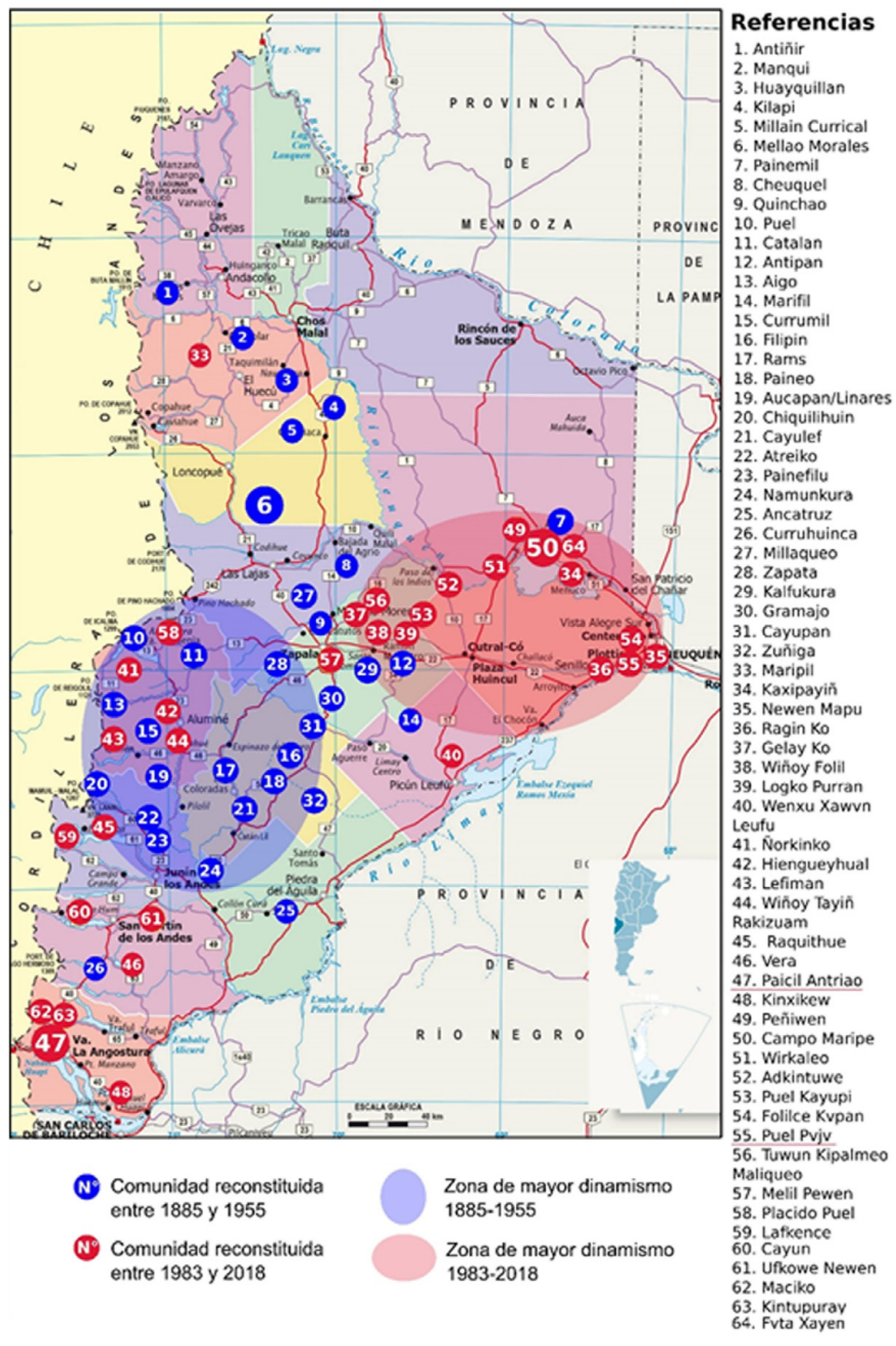

Imagen 1: Comunidades dentro de la Confederación Mapuche de Neuquén (2020)

Fuente: Elaboración propia en base a Piciñam y Rodríguez de Anca (2016) y trabajo de campo 


\section{La organización mapuche entre el derecho indígena y la realidad neoliberal: los noventa}

La última década del siglo XX trajo una serie de novedades para las organizaciones indígenas en Neuquén: se trató de una época de emergencias. La realidad de los procesos de reorganización de la vida comunitaria en este momento estuvo cruzada fundamentalmente por dos cuestiones paralelas y contradictorias. Por un lado, la progresiva consolidación en el derecho internacional de un nuevo paradigma, que consideraba al derecho indígena como una cuestión vinculada a medidas especiales, así como a marcos culturales específicos y diferenciados de la cosmovisión occidental (Charters \& Stavenhagen, 2010); por otro, la realidad concreta de un proceso nacional y provincial de ajuste económico y reestructuración estatal neoliberal que asumía formas de pauperización y caída de los niveles de vida de la población (Favaro, 2002). Como respuesta a ello, la provincia de Neuquén se configuraba como un espacio de agudización del conflicto social, cuyos mayores exponentes fueron los levantamientos populares de las localidades petroleras de Cutral Có y Plaza Huincul, y las protestas docentes (Aiziczon, 2005).

A mediados de la década, una serie de conflictos territoriales ( $\mathrm{Fa}-$ laschi, 1999) marcó la emergencia de otra región dentro de la provincia como nuevo punto nodal en términos de los procesos de organización. Las denuncias por contaminación ambiental y por el uso y ventas de tierras indígenas a las empresas petroleras (Semorile, 2008) colocaron al este de la provincia como una zona que iba a adquirir cada vez mayor dinamismo. El este provincial se había configurado históricamente como una zona a la que fueron expulsados los pequeños productores de ganado caprino -indígenas y no indígenas-, previamente asentados en el área cordillerana y precordillerana, y cuyas tierras de mejor calidad fueron apropiadas por grandes terratenientes (Bandieri, 1991). Siendo primero considerados marginales, por su escasa calidad para la producción ganadera, los suelos del este fueron luego codiciados para explotar hidrocarburos.

La situación provincial tuvo injerencia en el reinicio de los procesos comunitarios y en la emergencia de una nueva zona dinámica, específicamente en relación con el impacto de la Ley No 24145 de federalización de los hidrocarburos y privatización de Yacimientos Pe- 
trolíferos Fiscales (YPF). El primer gobierno de Jorge Omar Sobisch, iniciado en 1991, significaba el inicio de un cambio de carácter dentro del partido hegemónico ${ }^{4}$ provincial (Rafart, 2009). En efecto, desde su fundación en la década de 1960 hasta 1990, el modelo del Movimiento Popular Neuquino (MPN) se había basado en la expansión del gasto público, la asistencia a los sectores vulnerabilizados de la población y su colocación como Estado empleador (Favaro \& Bucciarelli, 2001). Con el respaldo de Sobisch al modelo neoliberal nacional se empezaba a consolidar un cambio de carácter a través del cual el MPN se iría consolidando como el aliado estratégico de las empresas petroleras multinacionales, apoyando la primacía del sector privado en la actividad económica y buscando tornar "eficiente" a la administración pública. A raíz de ello, en los 90, la provincia apoyó la privatización de empresas como Yacimientos Petrolíferos Fiscales (YPF), Gas del Estado e Hidroeléctrica Norpatagonia (Hidronor), y recortó los salarios de los trabajadores del sector público.

Desde la década de 1980 emergían las organizaciones y comunidades del tercer tipo en los espacios urbanos y las cuales iban a tener un rol fundamental durante los años 90. Por un lado, surgían para dar apoyo a las comunidades del interior rural que se encontraran alejadas del centro de toma de decisiones políticas de la provincia y, por el otro, estaban compuestas por una generación cuyos ámbitos de socialización eran compartidos con el pueblo neuquino, lo cual en algunos casos implicó trayectorias militantes en el seno de sindicatos, como el de los trabajadores de la construcción. A partir de 1993, algunas de estas comunidades se articulaban con la Confederación Indígena dentro de la Coordinadora de Organizaciones Mapuche (COM) (Valverde, 2005).

Además de los conflictos a raíz de la explotación de hidrocarburos, las políticas neoliberales implicaron el avance de la especulación inmobiliaria y del negocio turístico en otras zonas de la provincia, como el sur cordillerano. Localidades como San Martín de los Andes, Villa Pehuenia y Villa La Angostura se fueron configurando como destinos turísticos para las clases dominantes argentinas (Trentini,

4 Nos referimos de esa forma al Movimiento Popular Neuquino (MPN), de origen neoperonista, ya que desde su fundación en 1961 (en contexto de proscripción del peronismo) y hasta la fecha ha sido la fuerza política gobernante a nivel provincial de forma ininterrumpida. 
2012). Toda la zona de influencia del lago Nahuel Huapi había pasado previamente por un proceso de manipulación de su paisaje, su flora y su fauna para concordar con el imaginario de una "Suiza argentina" (Navarro Floria, 2008). Esto supuso para las comunidades un progresivo despojo territorial en función del crecimiento de la especulación inmobiliaria y una necesidad de inserción como mano de obra poco calificada en los emprendimientos turísticos en respuesta a la insuficiencia de recursos para alcanzar la subsistencia (García \& Valverde, 2007). Esto conformó la antesala de los procesos de reconstitución comunitaria del siglo XXI.

Desde la COM, se logró la gravitación de nuevas matrices de pensamiento militante en las comunidades del interior en el marco de un conflicto ocurrido en el Departamento de Aluminé -en el corazón de la que hemos llamado la primera zona de dinamismo organizativo- en $1995^{5}$. Acerca de este conflicto, es necesario resaltar que el núcleo de la dirigencia de la Confederación Indígena -que mantenía el ya mencionado vínculo incómodo con el gobierno- se vio imposibilitado para profundizar en las medidas de protesta, tras lo cual un sector alineado con la COM impulsó una línea política novedosa. Esta línea incluyó la toma de medidas de ejercicio directo del derecho territorial sin mediar acuerdos con el Estado provincial. El conflicto obró como parteaguas en la historia mapuche, puesto que dio a conocer la existencia de sectores que portaban una renovada perspectiva política que, a partir de entonces, disputarían su hegemonía dentro de la Confederación Indígena Neuquina hasta ganarla a principios de los años 2000.

Nos han educado para eso, para decirnos "bueno, recibí el plan, quedate quietito ahí, espera que ya en las otras elecciones vamos a necesitar tu voto" (...) Mi tío, que en ese momento era uno de los caciques, prefirió abrirse, y no enfrentarse con la gente de otras comunidades, y fue visto como un tipo que no entendió el fondo de la cuestión. Si él hubiera entendido el fondo de la cuestión se hubiese quedado ahí y hubiese dicho "bueno, no me peleo con ustedes pero los apoyo". (Entrevista a S. Currumil, 23 de enero de 2015).

5 Este conflicto ha sido estudiado en profundidad, y para conocer sus detalles, puede recurrirse a Papazian (2019). 
La nueva tonalidad de las acciones colectivas iba en sintonía con la situación de agudización del conflicto social en toda la provincia. Al mismo tiempo, las reivindicaciones mapuches podían anclarse ahora en la concepción en desarrollo de la existencia de un conjunto de derechos específicos, portados por los indígenas en función de su situación histórica de desigualdad. La gestación de este cambio de paradigma desde uno anterior que tenía al derecho internacional abocado a la integración en la sociedad mayor fue fruto de la presencia indígena en los organismos internacionales (Daes, 2010). Asimismo, tuvo su correlato en el territorio: los nuevos núcleos militantes criticaron las intenciones paternalistas e integracionistas de la política provincial y comenzaron a defender el derecho a decidir sobre las medidas y planes que afectaran sus territorios, a ser consultados y a proyectar una forma de vida alternativa con autonomía. En el siguiente acápite analizaremos algunas características de esta perspectiva política que se consolidó en el siglo XXI.

\section{Territorio, autonomía e interculturalidad: la consolidación de un proyecto mapuche}

Durante las últimas dos décadas, la organización supracomunal se ha consolidado, lo que ha brindado un marco de apoyo a las comunidades, un impulso a sus reivindicaciones territoriales y una dirección al proceso político del pueblo mapuche en la provincia. La redacción de estatutos autónomos por parte de los lof y la refundación de la organización supracomunal como Confederación Mapuche de Neuquén fueron los eventos iniciales del proceso. Una de las manifestaciones de la consolidación fue el acompañamiento más cercano de los procesos de las comunidades en rearmado; y otra, fruto de la capacidad de vinculación efectiva con las mismas, fue el trabajo de elaboración y publicación de su proyecto económico, político y cultural en el que se definieron como el "gobierno mapuche".

La forma de responder a la renovada amenaza que implicaban los procesos extractivos tuvo, a partir de la década de 1990, la apoyatura sobre los nuevos marcos legales y sobre la experiencia de la confederación mapuche. El conflicto social estallaba especialmente en las zonas afectadas por la explotación de recursos hidrocarburíferos, mineros y turísticos, y, en su contexto, se inició la recomposición formal de nu- 
merosas comunidades. Como consecuencia de este panorama presente en todo el país, el Estado nacional recurrió en 2006 a la sanción de la Ley No 26160 que decretaba la emergencia en materia de posesión de la tierra y ordenaba el cese de desalojos hasta la concreción de relevamientos territoriales para definir las extensiones de los territorios de las comunidades indígenas.

Ya que las comunidades sujetas a ser relevadas eran aquellas que contaban con el reconocimiento estatal, se configuró un juego de piezas que aceleró y multiplicó los pedidos de registro de lof en la provincia y a nivel nacional. En la dimensión ideológica, aquello tuvo un impacto de solidificación de la comunidad como punto de referencia identitario, lo cual se tornó particularmente visible en las jóvenes generaciones (Aguirre, 2020). Como forma de ordenamiento del territorio, la confederación mapuche ejecutó una división de este en cinco consejos zonales a partir del año 2007 -luego, el número se amplió a seis a mediados de la década de 2010. Su funcionamiento comenzó a ser la vía de transmisión y comunicación entre el cascarón de la organización supracomunal y los lof, estando compuestos por autoridades políticas, administrativas y culturales provenientes de los mismos.

Los procesos de reconstitución comunitaria y reivindicación indígena que cobraron impulso en la primera década del siglo XXI tuvieron como respuesta una contraofensiva de los sectores dominantes regionales y de los titulares registrales de los lotes que empezaban a ser parte de las recuperaciones territoriales. Por un lado, aumentaron las causas penales contra mapuches por presuntas usurpaciones y otros delitos hacia la propiedad (Observatorio de Derechos Humanos de Pueblos Indígenas, 2010). Por el otro, algunos sectores de la burguesía neuquina, con vínculos personales y familiares con el partido provincial gobernante, organizaron la Asociación en Defensa de la Ley (ADELEY) (Río Negro, 7 de noviembre de 2009) con el fin específico de oponerse a la confederación mapuche. A partir del reinicio de los procesos de reconstitución comunitaria, se impulsaron, además, ciertas estrategias de deslegitimación y cuestionamiento que llegaron a los medios de comunicación nacionales. Los argumentos esgrimidos con tales fines se basaban en la asociación de las prácticas mapuches con la violencia extrema, a las que se les endilgó una finalidad separatista (Aguirre, 2016). Sin embargo, estas nociones contrastan con los ejes 
centrales del proyecto político de la Confederación Mapuche y con las prácticas impulsadas en las comunidades durante la última década.

El afianzamiento de la organización supracomunal trajo aparejadas las recuperaciones de puntos nodales para la reproducción cultural: celebraciones ${ }^{6}$, constitución de instituciones normativas y de justicia propias ${ }^{7}$, el idioma ${ }^{8}$ y la transmisión mediante el ejemplo de la práctica ${ }^{9}$. Estas cuestiones se encuentran reflejadas en los procesos de las comunidades. En el caso del idioma, como necesidad de los lof, e impulsado por la confederación, se empezó a buscar la expansión del aprendizaje y uso del mapuzugun. La transmisión cultural por medio de la práctica renació como consecuencia natural de los procesos de reconstrucción de las comunidades. Al estos darse en contextos de conflicto social, sin embargo, los "haceres" prácticos que se comenzaron a transmitir fueron de cualidades novedosas. Por ejemplo, los testimonios dejan asentada una preocupación recurrente por legar a los hijos y nietos el ejemplo de la lucha: "lo que estamos haciendo, lo estamos haciendo por nuestros hijos, por nuestros nietos, por nuestros bisnietos, que el día de mañana ellos tengan que decir 'esto me lo dejó mi abuela o mi mamá"' (Entrevista a J. Campo por P. Piciñam, septiembre de 2014). En el mismo sentido, se empezó a realizar una introducción temprana a los niños sobre las dinámicas políticas por medio de su presencia en espacios de debate y toma de decisiones -muy por el contrario al escenario del siglo XX descrito en las memorias de los indígenas, en las que se relata que ciertos espacios, así como el idioma, se encontraban vedados para los jóvenes ${ }^{10}$.

6 El Centro de Educación Mapuce Norgvbamtuleayiñ inició la recuperación de actividades y ceremonias centrales en la vida cultural.

7 Se elaboraron propuestas para el reconocimiento de instituciones propias para la generación de normas y administración de justicia (Meli Wixan Mapu y Nor Feleal, respectivamente) y su funcionamiento en articulación con la Legislatura y el Poder Judicial neuquinos.

8 Se emprendió la enseñanza del mapuzugun en las comunidades y se adoptó un grafemario para el desarrollo escrito del idioma (Confederación Mapuce de Neuquén, 2010).

9 "Los ejemplos en la práctica son la mejor manera que tenemos como pueblo para transmitir estos conocimientos que están depositados en nuestro KVGA (origen familiar y territorial más ancestral) y son heredados y preservados por nuestra descendencia" (Confederación Mapuce de Neuquén, 2010, p. 34).

10 Las hermanas Campo, de la tercera generación de la comunidad Campo Maripe, aseveraban que, durante su infancia, tanto el habla del mapuzugun como la discusión de 
La consolidación de la confederación también necesitó de la definición clara de una serie de conceptos que fundamentaron el proyecto económico y político que se fue elaborando. Por esta razón, fue publicado en 2010 el Kvme Felen -libro en el que se expresaban los principales puntos para el "buen vivir" mapuche. Por un lado, se desarrolló allí una concepción laxa de la identidad, atravesada por la fuerte influencia del contexto del conflicto social: "ser mapuce es practicar la vida mapuce y defenderla" (Confederación Mapuce de Neuquén, 2010, p. 34). Aquel concepto se definió como anclado en el territorio: "en él radica nuestro origen, nuestro ser y desde él es que ejercemos nuestro gobierno" (p. 12). Los procesos de vinculación con el territorio se entendieron también diferenciados según regiones, dando lugar a la noción de identidades territoriales (Confederación Mapuce de Neuquén, 2010). Estas consideraciones le han permitido a la confederación consolidarse con atención a las diferencias regionales, tomando en consideración especialmente a las variaciones lingüísticas presentes en el territorio y sin perder la definición unitaria del pueblo mapuche. "Este término [pueblo] implica entonces el ejercicio de una autonomía que es la que efectivamente conduce a la realización plena de los derechos reconocidos como pueblo originario" (p. 52).

En el plano económico, se planteó una visión opuesta a la lógica capitalista y con dos pilares fundamentales: la provisión de recursos en función de las necesidades específicas y el ejercicio del trabajo basado en el principio de la reciprocidad (Confederación Mapuce de Neuquén, 2010). Estos vectores se vincularon con la propuesta de un uso de los recursos naturales de carácter racional, la satisfacción de las necesidades de la población y la priorización de la demanda local frente a la externa (Confederación Mapuce de Neuquén, 2010). Para que ello fuese posible, se propuso la creación de jurisdicciones indígenas y municipios de gobernanza mapuche e intercultural que le permitiera al pueblo indígena la decisión sobre el uso y aprovechamiento de los recursos. Se evidencia, así, la abierta contradicción entre el proyecto mapuche y el modelo de acumulación vigente, lo cual significó que la reivindicación de derechos específicos debía complementarse con reclamos de mayor amplitud.

problemas ligados a los negocios ganaderos de la familia eran dimensiones exclusivas de los adultos (Entrevista a M. Campo, S. Campo y M. Campo, 16 de noviembre de 2016). 
El planteo mismo de los alcances de la interculturalidad como método de coexistencia, pero también de radical modificación de las bases estructurales y superestructurales de la sociedad argentina, permite comprender que en ella está implicado un conjunto de problemáticas comunes al pueblo mapuche y al argentino: "Es necesario que nuestra propia cosmovisión cumpla el rol de revisar las bases actuales de la racionalidad capitalista, el monoculturalismo, el patriarcado y el racismo" (Confederación Mapuce de Neuquén, 2010, p. 50). La coexistencia que se proyecta contiene tanto el componente de la interculturalidad como de la autonomía. La primera es comprendida como un vínculo pedagógico (Confederación Mapuce de Neuquén, 2010), lo cual se expresa en las prácticas del lof Puel Pvjv que se analizarán en la próxima sección. La segunda, por su parte, implica tanto un horizonte de expectativa como una posibilidad presente. Para lograr la autonomía, el proyecto nacional mapuche propone, como ya mencionamos, la creación de regiones interjurisdiccionales en las que el pueblo indígena pueda regular el uso del territorio y los recursos en el marco de un Estado unitario que se reconozca plurinacional e intercultural. Por otro lado, también se comprende a las prácticas de lucha en tanto pueblo como instancias de ejercicio de la autonomía en el presente, a lo que ya hemos hecho referencia.

En el proceso de consolidación de la confederación, al calor de los conflictos territoriales, el pueblo mapuche elaboró vínculos con organizaciones de derechos humanos, como la Asamblea Permanente por los Derechos Humanos de Neuquén (APDH); con profesionales y militantes de partidos políticos y organizaciones, junto a quienes conformaron el Observatorio de Derechos Humanos de Pueblos Indígenas (ODHPI); con instituciones como la Universidad Nacional del Comahue; con partidos políticos de diversas ideologías, en su mayoría nacidos del peronismo o de la izquierda argentina ${ }^{11}$; y con sindicatos, como el de trabajadores estatales (Asociación de Trabajadores del Estado) ${ }^{12}$ y de docentes (Asociación de Trabajadores de la Educación

11 Partidos de izquierda de tendencias ideológicas trotskistas y maoístas fueron frecuentes aliados en contextos de acciones colectivas específicas del pueblo mapuche (Todo Noticias, 28 de agosto de 2013).

12 Ha habido una vinculación específica con los trabajadores estatales de la Asociación de Trabajadores del Estado (ATE) en el contexto de la proyección dentro del Parque Nacional Lanín (Magnani, 2012). 
de Neuquén ${ }^{13}$ y Asociación de Docentes de la Universidad Nacional del Comahue $)^{14}$; incluso, a nivel local, las comunidades contaron con el soporte de sectores organizados en instituciones y ONG.

Los profundos vínculos con los grupos movilizados de la sociedad argentina impactaron en la línea política de la confederación. Por un lado, las tramas de poder denunciadas fueron incluyendo un foco cada vez más amplio y, por el otro, la diferenciación frente al pueblo argentino tuvo un viraje desde el hincapié exclusivo de ciertas reivindicaciones propias. Se pasó de ello a la enunciación de históricas problemáticas compartidas y a un enfoque de valorización de la unidad con el mismo que se manifestó en el armado de organizaciones multisectoriales -como la Multisectorial contra la Hidrofractura en 2013 (Riffo, 2016) - o de frentes de articulación en lugares específicos.

Un referente de la confederación señaló acerca de uno de los casos aquí estudiados, Paicil Antriao, que "era muy poco favorable que estuviéramos a parte de la sociedad en contra" (Entrevista a F. Nawel, 5 de junio de 2018). Una lectura sobre lo "poco favorable" que resultaba carecer del apoyo de algún sector de la sociedad no mapuche abrió paso a la sedimentación de la idea de que era posible distinguir enemigos en común en base a situaciones de opresión, despojo e injusticia que atravesaran tanto al pueblo mapuche como al "blanco". Esta noción se fue expresando de forma cada vez más clara en las manifestaciones públicas de los principales referentes de la confederación:

A partir de la "conquista del desierto", esto dejó de llamarse Waj Mapu y empezó a llamarse Patagonia, y hoy a partir de lo que es la nueva conquista del extractivismo, esto ha dejado de llamarse Neuquén y ha pasado a llamarse Vaca Muerta. Y creo que es un nuevo capítulo más del saqueo, de la invasión y del desprecio, hoy ya no solamente contra el pueblo mapuche sino contra los pueblos que

13 El gremio de docentes de enseñanza inicial y media, Asociación de Trabajadores de la Educación de Neuquén (ATEN), colaboró con la confederación en el armado de un proyecto de presencia de la bandera mapuche (wenu foye) en actos escolares. La aprobación del proyecto corrió por cuenta del Consejo Provincial de Educación.

14 La Asociación de Docentes de la Universidad Nacional del Comahue (ADUNC) realizó un acompañamiento de los reclamos de la confederación de manera permanente. Esto incluyó el endoso de un proyecto para la inclusión del derecho indígena dentro del plan de estudios de la carrera de derecho de la Universidad Nacional del Comahue. 
viven en este lugar. Así como contra el pueblo mapuche, contra el pueblo argentino, neuquino en este caso. (Nawel, 2020).

Estas reflexiones se sustentan en una visión de la historia argentina: "todavía falta para lograr la definitiva independencia de lo que son los intereses imperialistas, capitalistas" (Nawel, 2020). En este sentido es posible observar cómo autonomía e interculturalidad se entrecruzan: el buen vivir es definido a través de la posibilidad de decidir cómo vivir, aunque en ello se tiene en cuenta que hay "otro pueblo que ahora vive en este lugar" (Nawel, 2020), así como que "es necesaria la acción coordinada, la unión de todos y todas las que están luchando" (Nawel, 2020).

La unidad se extiende a la forma de organización política, en tanto la relación con el Estado que se pretende es una

de respeto y reconocimiento mutuo (...) Cuando inician esas campañas montadas, armadas de los mapuche violentos, de los mapuche terroristas, les decimos: no hay pueblo más legalista que el mapuche, si le estamos pidiendo [al Estado] todo el tiempo [que] cumplan con la ley, cumplan con la Constitución. (Entrevista a J. Nawel, realizada por el Director de Culturas Originarias de la Provincia de Neuquén, septiembre de 2020).

El proyecto político contiene una reivindicación político-cultural que sostiene la necesidad de mantener la identidad en un contexto de permanente vinculación con la sociedad argentina. En este punto, se expresa la interculturalidad como enriquecimiento mutuo, es decir, como relación pedagógica.

Lamentablemente, el sistema le prohíbe al pueblo mapuche aportar todo su bagaje de conocimiento porque vivimos en un modelo cultural donde es absolutamente monocultural, donde lo mapuche no tiene cabida, es una especie de subcultura, o de cultura atada al pasado... Para construir un nuevo modelo civilizatorio es fundamental volver a reivindicar los conocimientos y las prácticas del pueblo mapuche, ese es el aporte que nosotros necesitamos hacer, pero para eso también necesitamos un interlocutor dispuesto a escuchar, dispuesto a utilizar esos elementos. (Entrevista a J. Nawel, realizada por el Director de Culturas Originarias de la Provincia de Neuquén, septiembre de 2020). 
El uso de la noción de "modelo civilizatorio" para designar formas de producción y organización alternativas que incluyan a indígenas y no indígenas en convivencia se está extendiendo entre los referentes mapuche. Una formulación previa de esta idea puede encontrarse en el Kume Felen: "un proyecto de vida no puede ser durable ni sustentable si no es ordenado y apropiado por los pueblos que la habitan (...) Esta responsabilidad no es una responsabilidad únicamente para el mapuce" (Confederación Mapuce de Neuquén, 2010, p. 57). La comprensión de la gestación de este enfoque permite explicar ciertos aspectos fundamentales del trabajo que la organización supracomunal desarrolló en las comunidades con miras a afianzar en estas una línea de acción política entendida como la más propicia para hacer prosperar las reivindicaciones originarias y el propio proyecto como pueblo. En efecto, el cuadro general de resistencia al avance de actores privados sobre el territorio se compuso tanto de conflictos basados en reivindicaciones específicas como de otras de carácter más amplio, especialmente de contenido ambiental. Al calor de estas, se aceleró el proceso de reconstitución de las comunidades de segundo y tercer tipo. Esta no fue la única vía de vinculación con sectores no mapuches, ya que, al asumirse la interculturalidad como una relación pedagógica, algunas comunidades abrieron espacios ceremoniales o culturales a la participación "blanca", fortaleciendo alianzas que se expresaban ya en el apoyo mutuo frente a las disputas territoriales.

\section{La Confederación Mapuche y las comunidades frente a los procesos extractivos en el siglo XXI}

En este acápite, analizaremos de qué modo la organización supracomunitaria impulsó en dos comunidades -Paicil Antriao y Puel Pvjvel desarrollo de una línea política que articuló territorio y autonomía, con el objetivo de esbozar algunos alcances y límites de las prácticas llevadas adelante. Los casos fueron seleccionados en función de la integración en estas comunidades de referentes de la confederación mapuche.

En la región que hemos denominado la primera zona de dinamismo, por la concentración de gran cantidad de comunidades reconstituidas durante la primera mitad del siglo $\mathrm{XX}$, ha adquirido central 
relevancia la disputa territorial en torno a las explotaciones turísticas (Radovich \& Balazote, 2009). En torno al año 2000 comenzó su proceso de reconstitución la comunidad Paicil Antriao, cuya presencia en la zona es verificable en los documentos escritos a partir de 1897 (Ministerio de Agricultura de la Nación, Expediente №118/36, fojas 29, 31 y 33). Los progresivos despojos territoriales a manos de privados y del Estado en sus diferentes niveles habían generado el desmembramiento de las familias y la migración forzada de algunos de sus integrantes al ámbito urbanizado a partir de la década de 1940 (Ghioldi, 2010). En 2003 se recuperaron tierras dentro del territorio de uso tradicional y a lo largo de la década se tensionó el conflicto con los privados que habían sido hasta entonces propietarios ausentes (Nawel, 2013).

En la segunda década del siglo XXI, la Confederación Mapuche de Neuquén comenzó un proceso de acompañamiento a la comunidad, debido a que esta estaba perdiendo su cohesión interna por las estrategias que los privados y el Estado provincial llevaban adelante para hacerla retroceder en sus reivindicaciones, lo que se convirtió en judicialización, que ya había acabado en dos desalojos altamente violentos. La situación era leída por la organización supracomunal como crítica, en tanto que la resolución de los conflictos se veía obturada por la criminalización y por un enfoque político interno que implicaba prácticas que suscitaban un gran rechazo por parte de la sociedad:

Se generó al principio una imagen así muy muy fea de la comunidad, sobre todo cuando llegan unos personajes ahí que reivindicaban el derecho, pero de una forma que no estaban de acuerdo, una metodología totalmente ajena a la nuestra... Hubo que hacer un trabajo muy fuerte para que muchos compañeros, compañeras de la sociedad de Villa La Angostura empezaran a entender que lo que estaba haciendo el lof era reivindicar ese derecho justo. (Entrevista a F. Nawel, julio de 2018).

Durante la década de 2010, se profundizaron los avances sobre el territorio. En el año 2015, una resolución del Ministerio de Desarrollo Territorial ( $\left.\mathrm{N}^{\circ} 371\right)$ dispuso que, bajo ciertas condiciones, lotes menores a 2,5 hectáreas podían ser administrados acorde a la voluntad del municipio. Sin embargo, esto iba en sentido contrario a lo expre- 
sado por la Ley nacional № 26331, conocida como Ley de Bosques, y de la Ley provincial $\mathrm{N}^{\circ} 2780$, de ordenamiento de los bosques nativos en la provincia de Neuquén. En efecto, la Ley Nacional de Bosques, en su artículo 9, estableció una jerarquización de áreas, siendo una de ellas la Categoría I y señalada como de alto nivel de conservación, en la cual se prohíbe la transformación. Por su parte, la Ley Provincial de Bosques estableció que la zona al este del lago Correntoso caía dentro de dicha categoría. De esta forma, un marco regulatorio zonal se impuso sobre las leyes nacional y provincial. Esto resultó en la autorización de un loteo de casi 90 hectáreas, dividido en 21 parcelas, vendidas a un fideicomiso con la finalidad de la explotación turística dentro del territorio tradicionalmente habitado por la comunidad Paicil Antriao.

La posibilidad de articular una defensa del territorio nació del trabajo de vinculación con las organizaciones de la sociedad angosturense, especialmente ONG e instituciones defensoras del medio ambiente, y propiciado por la comunidad y la Confederación Mapuche de Neuquén (entrevista a V. Buchile, 14 de junio de 2018). La colocación del eje político en la defensa de un derecho que incluyó, pero al mismo tiempo excedió, las especificidades del derecho indígena fue el factor que atizó la unidad en la reivindicación. Se elaboró una consigna por la defensa de los bosques nativos, y se instaló un resguardo territorial por medio de la recuperación directa como respuesta al loteo y al inicio del desmonte con el fin de iniciar obras privadas. El apoyo de diversas organizaciones al reclamo reforzó la táctica de colocar como blanco político al Estado provincial, en tanto se encontraba violando sus propias regulaciones y las nacionales.

En el desarrollo de las acciones de protesta, fue evidente la diferencia en objetivos de cada sector. Una de las ONG se concentraba en acciones de reforestación de zonas desmontadas y apoyaba el resguardo territorial mapuche por medio de la colaboración con alimentos y otros elementos -como gasoil para el funcionamiento de un generador eléctrico- (Entrevista a E. Edelstein, 17 de mayo de 2020). Por otra parte, la comunidad realizó hincapié al momento de confrontar a las autoridades sobre sus derechos específicos a la consulta libre, previa e informada, acorde al Convenio 169 de la Organización Internacional del Trabajo -OIT- (Entrevista a V. Buchile, 14 de junio 
de 2018). A pesar de ello, la acción conjunta logró una gran difusión del caso, a raíz de la cual, a fines del 2018, el gobierno provincial desconoció públicamente haber autorizado el desmonte de la zona e instó informalmente a los propietarios a cesar en la urbanización (Diario Andino, 4 de diciembre de 2018).

La segunda comunidad cuyas prácticas analizaremos, Puel Pvjv (espíritu del este), se encuentra ubicada en las inmediaciones de la ciudad de Neuquén, y entre sus referentes se encuentran mujeres autoridades de la confederación mapuche. Actualmente y en conjunto con otra comunidad, Newen Mapu, se ha entablado un diálogo con el Estado municipal para el reconocimiento de 50 hectáreas en la zona de meseta del noroeste de la capital provincial. Esta negociación fue posible a partir de la composición de la fuerza política que llevó a Mariano Gaido -perteneciente al Movimiento Popular Neuquino- a la intendencia, que incluyó en coalición a un partido de la capital neuquina y con el cual algunos referentes mapuche han forjado cercanos vínculos [Unión de los Neuquinos (UNE)]. Puel Pvjv ha estado desplegando, con el apoyo de la Confederación, prácticas que resultan relevantes para nuestra indagación en dos sentidos.

Por un lado, las mujeres integrantes del lof y de la organización supracomunitaria se han dedicado a dictar cursos de diferentes temas -desde bibliotecas populares hasta la Universidad Nacional del Comahue- sobre la cosmovisión mapuche. Especialmente, en los últimos años, han decidido recuperar la medicina tradicional en estos espacios, como declaró la vocera de Puel Pvjv:

La realidad que tenemos hoy es la necesidad de dar cuenta de que existimos como mapuche, como comunidad, y que nosotros somos gente que seguimos manteniendo nuestra identidad. Y dar cuenta como en la ciudad se niegan nuestros derechos como mapuche como la ciudad pretende invisibilizarnos. En ese sentido nosotros estamos rompiendo barreras viviendo en la ciudad, tenemos derecho a tener un espacio territorial apto para desarrollarnos como comunidad. Es importante que se conozca que nosotros tenemos nuestras autoridades que hacen a nuestra organización política y social para comenzar un proceso real de relación intercultural (8300, agosto de 2017). 
Como se desprende del testimonio, esta comunidad expresa una problemática central para el pueblo mapuche en la actualidad, vinculada con el hecho de que, debido a los procesos históricos de despojo territorial y desmembramiento comunitario, la mayoría de la población indígena se halla residiendo en zonas urbanas (Entrevista a J. Nawel, realizada por el Director de Culturas Originarias de la Provincia de Neuquén, septiembre de 2020). La radicación se concentra en los barrios populares de la capital, imposibilitando la reunión en un espacio colectivo. Para esto, se recuperó un área de meseta en la zona periurbana de Neuquén, cedida en 2011 por el municipio en conjunto con otra comunidad. Sin embargo, esto no logró resolver la problemática territorial, puesto que el área -en el pasado, completamente marginal por sus condiciones geográficas y su distancia respecto del centro de la ciudad- se encuentra afectada por actividades vinculadas a la explotación de hidrocarburos.

Entre la concesión de 2011 -realizada por un intendente perteneciente al Frente para la Victoria- y las negociaciones actuales con el intendente del MPN recién mencionadas, tuvo lugar el mandato municipal con la reelección de un representante de la coalición Cambiemos (2011-2019). Durante esos años, se desarrolló una política de judicialización hacia las dos comunidades que redundó en múltiples intentos de desalojo. Frente a ellos, Puel Pvjv resaltó: "Necesitamos el apoyo de la sociedad que nos entienda y comprenda para acompañar este proceso de nuestro espacio comunitario" (8300, agosto de 2017).

El apoyo de diversos sectores movilizados de la sociedad capitalina se expresó, por un lado, en las jornadas de protesta contra la contaminación ambiental en las inmediaciones de un área utilizada como zona de depósito de residuos petroleros (Río Negro, 14 de julio de 2019). Las comunidades encabezaron el reclamo en torno a la existencia de los denominados basureros petroleros en la zona periurbana neuquina, debido a las consecuencias que la contaminación trajo para el desarrollo de la vida en estos espacios. Por el otro lado, la articulación también se manifestó en el acompañamiento en la reivindicación territorial. Esto se exhibió en la masiva concurrencia de personas no mapuches a la celebración del Wiñoy Xipantv (reinicio del ciclo anual) organizado por la confederación en junio del 2018 y realizada por primera vez en el territorio recuperado de la meseta. Esto fue considerado por los refe- 
rentes de la organización supracomunitaria como un evento histórico (registro de campo, 24 de junio de 2018).

Estas dos comunidades, orientadas y apoyadas por la Confederación Mapuche de Neuquén, elaboraron prácticas y demandas con amplitud política. Dentro de estas alianzas, la contradicción étnica entre los sectores en resistencia se colocó en un segundo plano frente al riesgo de la penetración extractivista y de la ofensiva de los sectores dominantes. Como vimos, en ambos casos, el reclamo socializado se refirió a daños ambientales producto de actividades que depredan bienes comunes. Asimismo, existen estudios que permiten plantear la duda acerca de los alcances de la interculturalidad en estos escenarios. Se ha señalado que las fuerzas sociales construidas en función de las reivindicaciones socioambientales suelen ser polifónicas y no retomar los intereses de los mapuche en juego (Weinstock, 2009), lo que, en parte, fue encontrado en uno de los casos analizados. Es necesario tener la precaución de que estas consideraciones no nos lleven a interpretar que los indígenas no registran o analizan estos datos de la realidad, puesto que entender que la lectura política de la situación queda por fuera de la mirada mapuche podría resultar en una subestimación de la capacidad estratégica de los pueblos originarios. La imbricación con sectores no indígenas ha permitido instalar de forma más eficiente y rápida ciertos debates, y torcer en algunos casos la voluntad de sectores políticos en el poder.

En otros lugares (Tozzini, 2014), ya ha sido señalada la importancia que reviste, desde la perspectiva mapuche, la concurrencia de otras comunidades o sectores no indígenas al territorio comunitario. Esto adquiere especial relevancia política y es comprendido como un gesto de reconocimiento que permite el fortalecimiento del colectivo indígena, de modo que la participación blanca en ceremonias tradicionales y en eventos políticos en territorio mapuche -ambas suelen ir de la mano con frecuencia- tiene un impacto positivo en la consolidación comunitaria y hace al vínculo de la interculturalidad bidireccional.

\section{Conclusiones}

El derrotero seguido con la Confederación Mapuche de Neuquén se ha basado en la elaboración de un proyecto nacional mapuche que, sobre todo en los últimos años, reconoce la necesidad de gestación de un 
proyecto civilizatorio en conjunto con el pueblo argentino y neuquino. Sostenemos que el viraje hacia la caracterización de la autonomía como dependiente de la interculturalidad, y de esta última como un vínculo pedagógico, se dio sobre la base de dos procesos que convergieron.

Por un lado, existe un debate interno que evaluó la aplicación de diversas líneas políticas: la basada en un vínculo de dependencia del Estado, que perdió hegemonía en el cambio de siglo, así como otras que implicaban estrategias que generaban amplios rechazos hacia los indígenas de la sociedad mayor, las cuales no lograron tornarse hegemónicas por la injerencia que la confederación logró sobre algunos procesos comunitarios. Por otro lado, dada la matriz productiva provincial -fuertemente anclada en los hidrocarburos y alineada dentro de un modelo de dependencia externa nacional-, el negacionismo existente hacia los pueblos originarios y las contraofensivas gestadas desde los sectores dominantes, se consideró que la mejor opción estratégica frente al avance de los procesos extractivos sobre territorios mapuche constaba de la construcción de fuerzas sociales amplias, con frecuencia vinculadas a reclamos ambientales, y la difusión entre la sociedad neuquina sobre las características culturales mapuche como forma de reivindicar la presencia actual del pueblo.

Esto contrasta con algunos estereotipos ampliamente difundidos en los medios de comunicación (Rocha Varsanyi, 2018), los cuales vinculan al pueblo mapuche de Neuquén con una intención separatista y con acciones extremas de violencia. Por el contrario, se avanzó en una caracterización del territorio, por un lado, como necesario y vertebrador de la identidad y la cultura y, por el otro, como elemento compartido con los otros pueblos que residen en el mismo espacio. Este registro, al mismo tiempo que diferencia el pueblo argentino de sus sectores dominantes y de la estatalidad, reconoce que la viabilidad de un proyecto civilizatorio alternativo no requiere la secesión, sino que el compromiso de quienes, llegados posteriormente a las tierras previamente dominadas por los indígenas, han desarrollado su vida allí y adquirido el derecho de proyectarse en el territorio. 


\section{Referencias}

8300. (7 de agosto de 2017). Lof Puel Pvjv: “Tenemos derecho a tener un espacio territorial apto para desarrollarnos como comunidad". Recuperado de http://www.8300.com.ar/2017/08/07/ lof-puel-pvjv-tenemos-derecho-a-tener-un-espacio-territorial-apto-para-desarrollarnos-como-comunidad/

Aguirre, S. (2016). La representación violenta de reivindicaciones territoriales y acciones colectivas: claves para el análisis de los discursos del pueblo mapuche y de la prensa nacional (1995-2015). Conflicto Social, 9(15), 12-40. Recuperado de https://publicaciones.sociales.uba.ar/index.php/CS/article/view/1800

Aguirre, S. (2020). Comunidad y territorio a través de testimonios orales de mujeres mapuche. Villa La Angostura, Neuquén, 1980-2018. Revista TEFROS, 18(1), 110-140. Recuperado de http://www2.hum.unrc.edu.ar/ojs/index.php/tefros/article/view/853/1098

Aiziczon, F. (2005). Neuquén como campo de protesta. En O. Favaro (Comp.), Sujetos sociales y politica: historia reciente de la norpatagonia argentina (pp. 128-150). Buenos Aires: La Colmena. Recuperado de http://biblioteca.clacso.edu.ar/Argentina/cehepyc-uncoma/20110414103131/favaro.pdf

Angelis de, M. (2012). Marx y la acumulación primitiva: el carácter continuo de los cercamientos capitalistas. Theomai, (26), 16-35. Recuperado de https://www.redalyc.org/ pdf/124/12426097003.pdf

Armida, M. (2017). Bolivia: reconfiguración y conflictividad social a diez años de la llegada del MAS al gobierno. En G. Galafassi y S. Puricelli (Comps.), Perspectivas críticas sobre la conflictividad social (pp. 155-170). Buenos Aires: Extramuros. Recuperado de http://revista-theomai.unq.edu.ar/Perspectivas_ criticas_conflictividad_social-(Interior\%20y\%20Tapas).pdf

Bandieri, S. (1991). Frontera comercial, crisis ganadera y despoblamiento rural. Una aproximación al estudio del origen de la burguesía tradicional neuquina. Desarrollo Económico, 31(122), 209-235. doi: 10.2307/3466832

Blanco, G. (2007). La ocupación de la tierra pública en Neuquén: política distributiva, formas de tenencia y uso del suelo (18801920). Mundo Agrario: Revista de estudios rurales, 14(7), 
218-246. Recuperado de http://sedici.unlp.edu.ar/handle/10915/13232

Blanco, G. (2012). El paisaje patagónico en el cambio de siglo: tierra, ganado y productores en el avance de la frontera productiva. Anuario Digital, (24), 149-167. Recuperado de https://rephip.unr.edu.ar/bitstream/handle/2133/3715/207-827-1PB. pdf? sequence $=1$ \&isAllowed $=y$

Borg Rasmussen, M. \& Lund, C. (2018). Reconfiguring frontier spaces: the territorialization of resource control. World Development, 101, 388-399. doi: 10.1016/j.worlddev.2017.01.018

Charters, C. \& Stavenhagen, R. (2010). Introducción. En C. Charters y R. Stavenhagen (Eds.), El desafío de la declaración. Historia y futuro de la declaración de la ONU sobre pueblos indígenas (pp. 1-16). Copenhague: International Work Group for Indigenous Affairs.

Confederación Mapuce de Neuquén. (Ed.). (2010). Propuestas para un Kvme Felen Mapuce. Neuquén, Argentina: Confederación Mapuce de Neuquén. Recuperado de http://www.unter.org. ar/imagenes/kvme-felen-Plan-de-vida.pdf

Consejo Federal de Inversiones. (1978). Análisis socioeconómico, aspectos culturales y tipología de las comunidades aborígenes del Neuquén. Buenos Aires: Consejo Federal de Inversiones. Recuperado de http://biblioteca.cfi.org.ar/documento/analisis-socioeconomico-aspectos-culturales-y-tipologia-delas-comunidades-aborigenes-del-neuquen/.

Daes, E-I. A. (2010). La contribución del grupo de trabajo sobre poblaciones indígenas a la génesis y evolución de la declaración de la ONU sobre los derechos de los pueblos indígenas. En C. Charters y R. Stavenhagen (Eds.), El desafio de la declaración. Historia y futuro de la declaración de la ONU sobre pueblos indigenas (pp. 50-81). Copenhague: International Work Group for Indigenous Affairs.

Dávalos, P. (2013). Extractivismo y teoría de las instituciones. Izquier$d a$, (32), 20-27. Recuperado de https://revistaizquierda. com/secciones/subversiones-intelectuales/extractivismoy-teoria-de-las-instituciones

Delrio, W. (2005). Memorias de expropiación. Sometimiento e incorporación indígena en la Patagonia 1872-1943. Buenos Aires: 
Universidad Nacional de Quilmes. Recuperado de http:// www.unq.edu.ar/advf/documentos/503644a024a59.pdf

Diario Andino. (4 de diciembre de 2018). Provincia rechazó el polémico proyecto de loteo del Correntoso. Diario Andino. Recuperado de https://www.diarioandino.com.ar/ noticias/2018/12/04/211447-provincia-rechazo-el-polemico-proyecto-de-loteo-del-correntoso

Escobar, A. (2015). Territorios de diferencia: la ontología política de los "derechos al territorio". Cuadernos de Antropología Social, (41), 25-37. Recuperado de http://revistascientificas.filo. uba.ar/index.php/CAS/article/view/1594

Falaschi, C. (1994). La Confederación Indígena Neuquina. Neuquén: Instituto Regional de Educación y Promoción Social, Asamblea por los Derechos Humanos.

Falaschi, C. (1999). Diferencia, conflictos y formación en la construcción de identidades. Caso de las comunidades mapuches de Loma de La Lata. Recuperado de http://www.mapuche.info/mapuint/LomaLata.html

Falero, A. (2015). La expansión de la economía de enclaves en América Latina y la ficción del desarrollo: siguiendo una vieja discusión en nuevos moldes. Revista Mexicana de Ciencias Agrícolas, 1, 145-157. Recuperado de http://www.redalyc.org/ articulo.oa?id=263139243020.

Favaro, O. (2002). Neuquén. La sociedad y el conflicto. ¿Viejos actores y nuevas prácticas sociales? Realidad Económica, 185, 110121. Recuperado de http://biblioteca.clacso.edu.ar/Argentina/cehepyc-uncoma/20110503100147/Neuquen.pdf

Favaro, O. \& Bucciarelli, M. (2001). Una experiencia populista provincial: Neuquén 1960-1990. Nueva Sociedad. Revista de Ciencias Sociales, 172, 54-64. Recuperado de http://biblioteca.clacso. edu.ar/Argentina/cehepyc-uncoma/20110426120045/favaro.pdf

Galafassi, G. (2014). Procesos de construcción social de los conflictos y modos de acumulación. Una correlación necesaria. En G. Galafassi (Comp.), Apuntes de acumulación: capital, Estado y procesos sociohistóricos de reproducción y conflictividad social (pp. 61-93). Buenos Aires: Extramuros, Theomai. Recuperado de http://theomai.unq.edu.ar/ApuntesDeACUMULCACION.pdf 
Galafassi, G. (2017). Conflictividad social, contradicción y complejidad: entre las clases y los movimientos sociales. En G. Galafassi y S. Puricelli, (Comps.), Perspectivas críticas sobre la conflictividad social (pp. 13-37). Buenos Aires: Extramuros.

Galafassi, G. \& Riffo, L. (2018). Del sueño de Cristóbal Colón al hoy llamado "extractivismo". Peripecias y avatares de un largo y continuo proceso de expropiación para la acumulación: una necesaria discusión crítica. Theomai, (38), 187-200. Recuperado de https://ri.conicet.gov.ar/bitstream/handle/11336/73075/CONICET_Digital_Nro.bfdb4edf-62c94abc-ba0d-14054562f9bf_A.pdf?sequence $=2$

García, A. \& Valverde, S. (2007). Políticas estatales y procesos de etnogénesis en el caso de poblaciones mapuche de Villa La Angostura, provincia de Neuquén, Argentina. Cuadernos de Antropología Social, (25), 111-132. Recuperado de http:// revistascientificas.filo.uba.ar/index.php/CAS/article/ view/4381

García Lineras, A. (2014). Identidad boliviana: nación, mestizaje y plurinacionalidad. La Paz: Asamblea Legislativa Plurinacional.

Ghioldi, G. (Comp.). (2010). Historias de las familias mapuche Lof Paichil Antriao y Lof Quintriqueo. Mapuche de la margen norte del lago Nahuel Huapi. Córdoba: Ferreyra Editor.

Gudynas, E. (2009). Diez tesis urgentes sobre el nuevo extractivismo. Contextos y demandas bajo el progresismo sudamericano actual. En J. Schuldt, A. Acosta, A. Barandiarán, A. Bebbington, A. Folchi, A. Alayza y E. Gudynas (Eds.), Extractivismo, política y sociedad (pp. 187-225). Quito: Centro Andino de Acción Popular, Centro Latinoamericano de Ecología Social.

Gudynas, E. (2013). Extracciones, extractivismos y extrahecciones: un marco conceptual sobre la apropiación de recursos naturales. Observatorio del Desarrollo, (18), 1-17. Recuperado de https://www.researchgate.net/publication/281748932_Extracciones_Extractivismo_y_Extrahecciones_Un_marco_ conceptual_sobre_la_apropiacion_de_recursos_naturales

Gudynas, E. (2014). Conflictos y extractivismos: conceptos, contenidos y dinámicas. Decursos, Revista en Ciencias Sociales, (27-28), 79-115. Recuperado de https://www.researchgate.net/publication/326191722_Conflictos_y_extractivismos_conceptos_contenidos_y_dinamicas 
Haesbaert, R. (2011). El mito de la desterritorialización. del "fin de los territorios" a la multiterritorialidad. México, D.F.: Siglo XXI.

Harvey, D. (2004). The "new" imperialism: accumulation by dispossession. Socialist Register, 40(1), 63-87. Recuperado de https:// socialistregister.com/index.php/srv/article/view/5811

Kropff, L. (2005). Activismo mapuche en Argentina: trayectoria histórica y nuevas propuestas. En P. Dávalos (Comp.), Pueblos indígenas, Estado y democracia (pp. 103-132). Buenos Aires: Consejo Latinoamericano de Ciencias Sociales, CLACSO.

Machado Aráoz, H. (2015). Conflictos socioambientales y disputas civilizatorias en América Latina: entre el desarrollismo extractivista y el buen vivir. Crítica y Resistencias. Revista de conflictos sociales latinoamericanos, 1(1), 19-42. Recuperado de https://ri.conicet.gov.ar/handle/11336/69892

Magnani, R. (26 de enero de 2012). Un manejo en conjunto con los mapuches. Página 12. Recuperado de https://www.paginal2. com.ar/diario/sociedad/3-186259-2012-01-26.html

Mançano Fernandes, B. M. (2005). Movimentos socioterritoriais e movimentos socioespaciais. Observatorio Social de América Latina, (16), 273-283. Recuperado de http://biblioteca.clacso. edu.ar/clacso/osal/20110312111042/34MFernandes.pdf

Ministerio de Agricultura de la Nación. (1936). Expediente No 118, 1936. Archivo Documental, Archivo del Museo de la Patagonia, Fondo de la Administración de Parques Nacionales, San Carlos de Bariloche, Argentina.

Navarro Floria, P. (2008). El proceso de construcción social de la región del Nahuel Huapi en la práctica simbólica y material de Exequiel Bustillo (1934-1944). Revista Pilquen, 10(1), 1-14. Recuperado de http://revele.uncoma.edu.ar/htdoc/revele/ index.php/Sociales/article/view/2065/58559

Nawel, J. (Coord.) (2013). Huellas y senderos. Informe final de los resultados del relevamiento territorial, histórico, social y cultural de la comunidad mapuce Lof Paichil Antriao. Neuquén: Observatorio de los Derechos Humanos de los Pueblos Indígenas.

Nawel, L. (10 de octubre de 2020). Discurso público. Conversatorio "Xenofobia, racismo y discriminación contra el pueblo mapuche". Registro audiovisual de la autora. 
Observatorio de Derechos Humanos de Pueblos Indígenas (2010). Informe de la situación de los Derechos Humanos del Pueblo Mapuce en la Provincia del Neuquén 2009 -2010. Neuquén: ODHPI.

Papazian, A. (2019). Después del genocidio. Registros y memorias territorializadas en Pulmarí, Neuquén. Memoria Americana, 27(2), 80-97. Recuperado de http://revistascientificas.filo. uba.ar/index.php/MA/article/view/7162

Perelman, M. (2012). La historia secreta de la acumulación primitiva y la economía política clásica. Theomai, (26), 36-55.

Pérez Roig, D. \& Composto, C. (2014). Acumulación, crisis y despojo en el sistema-mundo. Aproximaciones para pensar el rol de América Latina en el capitalismo del siglo XXI. En G. Galafassi (Comp.), Apuntes de acumulación: capital, Estado y procesos sociohistóricos de reproducción y conflictividad social (pp. 17-61). Buenos Aires: Extramuros, Theomai. Recuperado de http://theomai.unq.edu.ar/ApuntesDeACUMULCACION. pdf

Piciñam, P. \& Rodríguez de Anca, A. (2016). El pueblo mapuce en Neuquén: ancestralidad, vigencia y proyección (Vol. 13, serie Pueblos indígenas en la Argentina). Buenos Aires: Ministerio de Educación y Deportes de la Nación. Recuperado de http:// www.bnm.me.gov.ar/gigal/documentos/EL005247.pdf

Puricelli, S. (2017). Contradicciones y confrontaciones en el campo mexicano. En G. Galafassi \& S. Puricelli, S. (Comps.), Perspectivas críticas sobre la conflictividad social (pp. 95-113). Buenos Aires: Extramuros.

Radovich, J. C. (2003). Impacto social de grandes aprovechamientos hidroenergéticos sobre comunidades rurales de Norpatagonia (Tesis doctoral inédita). Facultad de Filosofía y Letras, Universidad de Buenos Aires, Argentina.

Radovich, J. C. (2013). Los mapuches y el Estado neuquino: algunas características de la política indígena. RUNA, archivo para las ciencias del hombre, 34(1), 13-29. Recuperado de http:// revistascientificas.filo.uba.ar/index.php/runa/article/ view/560

Radovich, J. C. \& Balazote, A. (2009). Turismo y etnicidad. Una interculturalidad conflictiva en territorio mapuche, Neuquén, Argentina. En L. Tamagno (Coord.), Pueblos indígenas: in- 
terculturalidad, colonialidad, política (pp. 25-43). Buenos Aires: Editorial Biblos.

Rafart, G. (2009). Las "partes" del Movimiento Popular Neuquino. Un ensayo de interpretación de sus tiempos partidarios. Revista de la Facultad, 15(1), 93-113. Recuperado de https:// fadeweb.uncoma.edu.ar/extension/publifadecs/revista/ revista15/05GabrielRafart.pdf

Riffo, L. (2016). Hidrocarburos, fracking y resistencias sociales. Un análisis social de las políticas hidrocarburíferas contemporáneas en Argentina desde la provincia de Neuquén. Actuel Marx/Intervenciones, (20), 71-94.

Río Negro. (7 de noviembre de 2009). Crean entidad que se opone a las usurpaciones. Río Negro. Recuperado de https://www. rionegro.com.ar/crean-entidad-que-se-opone-a-las-usurpaciones-LVHRN1257564888100/

Río Negro. (14 de julio de 2019). El "lado B" de Vaca Muerta: el lento traslado de los residuos petroleros. Río Negro. Recuperado de https://www.rionegro.com.ar/un-lado-b-de-vaca-muerta-que-salpica-hasta-la-capital-neuquina-1037477/

Risio di, D., Gavaldà, M., Pérez Roig, D. \& Scandizzo, H. (2012). Zonas de sacrificio. Impactos de la industria hidrocarburifera en Salta y Norpatagonia. Buenos Aires: Observatorio Petrolero Sur, América Libre. Recuperado de https://opsur.org. ar/2012/05/03/libro-zonas-de-sacrificio-impactos-de-laindustria-hidrocarburifera-en-salta-y-norpatagonia/

Rocha Varsanyi, A. (2018). Creación del enemigo público mapuce: un análisis del discurso oficial sobre el conflicto territorial con el lof Campo Maripe entre 2013 y 2015. (En)clave Comahue. Revista Patagónica de Estudios Sociales, (24), 239-266. Recuperado de http://revele.uncoma.edu.ar/htdoc/revele/index.php/revistadelafacultad/article/view/2115

Rodríguez, E. (1978). Análisis socioeconómico, aspectos culturales y tipología de las comunidades aborígenes del Neuquén. Buenos Aires: Consejo Federal de Inversiones. Recuperado de http://biblioteca.cfi.org.ar/documento/analisis-socioeconomico-aspectos-culturales-y-tipologia-de-las-comunidades-aborigenes-del-neuquen/.

Semorile, Z. (diciembre, 2008). Acciones colectivas y movimientos sociales: aspectos teórico-metodológicos. Trabajo presentado 
en las V Jornadas de Sociología de la Universidad Nacional de La Plata, La Plata, Argentina.

Seoane, J. (2012). Neoliberalismo y ofensiva extractivista. Actualidad de la acumulación por despojo, desafíos de Nuestra América. Theomai, (26), 122-149.

Svampa, M. (2008). Cambio de época: movimientos sociales y poder político. Buenos Aires: Siglo XXI.

Svampa, M. (2017). Del cambio de época al fin de ciclo: gobiernos progresistas, extractivismo, y movimientos sociales en América Latina. Buenos Aires: Edhasa.

Todo Noticias. (28 de agosto de 2013). Neuquén: En un día de furia, la Legislatura aprobó el acuerdo entre Chevron e YPF. Todo Noticias. Recuperado de https://tn.com.ar/politica/neuquenen-un-dia-de-furia-la-legislatura-aprobo-el-acuerdo-entrechevron-e-ypf_408361.

Torres, L., Pastor, G., Grosso, M. \& Scoones, A. (2018). Turismo de lujo y extractivismo: la ruralidad como presa del capital. Reflexiones a propósito de Valle de Uco (Mendoza, Argentina). Scripta Nova, 22(585), 1-32. https://ri.conicet.gov.ar/handle/11336/92635

Tozzini, M. A. (2014). Pudiendo ser mapuche. Reclamos territoriales, procesos identitarios y Estado en Lago Puelo, Provincia de Chubut. Bariloche: Instituto de Investigaciones en Diversidad Cultural y Procesos de Cambio. Recuperado de https://ri.conicet.gov.ar/handle/11336/116083

Trentini, F. (2012). Ecología política y conservación: el caso del “comanejo" del Parque Nacional Nahuel Huapi y el pueblo mapuche. Revista Pilquen, (15), 1-11. Recuperado de http://ref. scielo.org/zfh593

Ulloa, A. (2001). El nativo ecológico: movimientos indígenas y medio ambiente en Colombia. En M. Archila \& M. Pardo (Eds.), Movimientos sociales, estado y democracia en Colombia (pp. 286-320). Bogotá: Universidad Nacional de Colombia, Centro de Estudios Sociales, Instituto Colombiano de Antropología e Historia.

Valverde, S. (2005). La historia de las organizaciones etnopolíticas del pueblo mapuche. Revista de Historia, (10), 167-177. Recuperado de http://revele.uncoma.edu.ar/htdoc/revele/index. php/historia/article/view/223 
Valverde, S. \& Stecher, G. (2013). Ruralidad, paradojas y tensiones asociadas a la movilización del pueblo Mapuche en Pulmarí (Neuquén, Argentina). Polis (Santiago), 12(34), 259-287. doi: 10.4067/S0718-65682013000100014

Walter, M. (2009). Conflictos ambientales, socioambientales, ecológico distributivos, de contenido ambiental... Reflexionando sobre enfoques y definiciones. Boletín ECOS, (6), 1-9. Recuperado de https://www.fuhem.es/media/ecosocial/File/Boletin\%20ECOS/Boletin\%206/Conflictos\%20ambientales_M. WALTER_mar09_final.pdf

Weinstock, A. (agosto, 2009). Acciones colectivas interculturales. Apuestas y dificultades. Trabajo presentado en el XXVII Congreso de la Asociación Latinoamericana de Sociología, VIII Jornadas de Sociología de la Universidad de Buenos Aires, Asociación Latinoamericana de Sociología, Buenos Aires, Argentina. Recuperado de http://www.aacademica.org/000062/2293.pdf 